pared with over 120 per million in Sweden and 100-120 per million in West Germany. ${ }^{5}$

There are a number of possible explanations for this rather striking difference. The incidence of heart block in Britain is the same as in other European countries, ${ }^{6}$ and this cannot be held accountable for the low rate of implantation here. Could it be that financial restrictions in Britain limit the number of pacemaker implantations? Again this is unlikely to be a factor of importance-pacemakers of either the fixed rate or demand variety (which are more expensive) may be ordered as indicated. Coming to the indications for pacemaker implantation, it is apparent that these vary from country to country-and even from centre to centre within one country-and this could account for the variation in implantation rates. There can be little argument about the patient with Adams-Stokes attacks or cardiac failure secondary to complete heart block: a pacemaker is mandatory, alternative forms of therapy such as the administration of long acting isoprenaline preparations having at best a transitory effect. Most patients in Britain are paced because of cerebral symptoms and heart failure with bradycardia. ${ }^{3}$ A smaller number have pacemakers implanted for the sick sinus syndrome, ${ }^{7}$ and an even smaller number for tachyarrhythmias which fail to respond to more conventional forms of treatment. ${ }^{8}$ However, asymptomatic patients with E.C.G. evidence of bundle-branch block and an abnormal axis are not usually considered for pacemaker implantation in Britain, whereas in other countries, notably the U.S.A., the reverse holds true. It is accepted in Britain that these E.C.G. changes are precursors of the development of symptomatic heart block, and it is known that the first Adams-Stokes attack may be fatal; opinion, however, varies as to exactly how frequently and how soon after the development of bundlebranch block and an abnormal axis symptoms actually occur, and there is an understandable reluctance to implant a pacemaker in the asymptomatic patient with E.C.G. abnormalities alone. $^{3}$ But as the mortality associated with pacemaker implantation is virtually zero there is now some justification for the view that prophylactic pacing is indicated in this situation.

Finally, a factor which may be of some relevance-but which is difficult to assess-in accounting for the low incidence of pacemaker implantations in Britain is the ambivalent and sometimes indifferent attitude of doctors to the subject. The average age of pacemaker patients is about 70 years, and faced with a patient in this age group with poor cerebral performance and incapacitating symptoms of cardiac failure it is all too easy to attribute the symptoms to senility. The relatives-and very often the patients themselves-when given the option of a pacemaker or conservative management readily choose the latter in the mistaken belief that what they regard as a major surgical procedure would not be tolerated because of general debility and advanced years. The doctor who is not familiar with pacemaker implantation (and many are not) may be unaware of the simplicity of the procedure and the low mortality and morbidity, and he may with the best of intentions concur with the wishes of the family. Doctors who are concerned in active pacemaker programmes are fully convinced of the rejuvenation and improvement in cerebral and general activity which often follows pacing-a fact which relatives and patients accept with incredulity and gratitudeand they are surely under some obligation to inform their colleagues, both in hospital and general practice, of the indications for and advantages of pacing. Better communication might go a long way towards increasing the referral of patients for pacemaker implantations. 1 Report of the Inter-Society Commission for Heart Disease Resources,

2 Roy, P. R., and Sowton, E., British Medical fournal, 1974, 4, 637.

3 Sowton, E., Hendrix, G., and Roy, P. R., British Medical fournal, 1974, 3, 155.

4 Sowton, E., in Cardiac Pacing, Proceedings of the 4th International Symposium, ed. J. Thalen. Assen, Van Gorcum, 1974.

5 Sykosch, H. J., in Cardiac Pacing, Proceedings of the 4th International Symposium, ed. J. Thalen. Assen, Van Gorcum, 1974.

- Eraut, C. D., Evans, R. C., and Shaw, D. B., British Heart fournal, 1973, $35,557$.

${ }^{7}$ Radford, D. J., and Julian, D. G., British Medical fournal, 1974, 3, 504.

8 Williams, D. O., and Davison, P. M., British Heart fournal, 1974, 36, 336.

\section{Blunt Pancreatic Injury}

Blunt injuries of the pancreas are fortunately uncommon in Britain, but the overall mortality is of the order of $20 \%$. Death shortly after abdominal injury is rarely due to damage to the gland itself; it usually results from lesions in other viscera or, quite frequently, haemorrhage from the major vessels in the vicinity of the pancreas. However, unless any pancreatic injury is treated properly substantial morbidity and also a considerable later mortality will result.

The clinical management of pancreatic trauma is difficult, since neither the diagnosis nor the operative handling of the situation are straightforward. The diagnosis can rarely be made with confidence preoperatively; while Yellin et al. ${ }^{1}$ found that the serum amylase was raised in $90 \%$ of their cases, Olson's study $^{2}$ of 176 unselected patients with blunt abdominal trauma showed that the amylase level was raised in 36 cases but only three of these had pancreatic damage. (There was in addition a tear in the body of the gland in one other patient, but his serum amylase was normal). A raised serum amylase should not, therefore, be taken as an indication for laparotomy-but clearly if a patient is collapsed or there are signs of spreading peritonitis exploration is essential.

Because pancreatic injury is uncommon it may not be considered at operation, especially if other organs are damaged. In all the reported series there have been instances where a small tear was missed even after a careful search. In some cases, however, the signs and symptoms may be equivocal; the serum amylase may not be raised, and laparotomy may not be indicated, so that the pancreatic injury may become evident only days or weeks later, usually when one of the complications develops-the commonest of these being a pseudocyst.

The second major problem surrounds the management of the laparotomy itself. Northrup and Simmons ${ }^{3}$ stressed that complications and mortality can be kept low only if the surgeon understands the nature of the injury and has a plan of management ready in his head. They listed four broad general principles.

Firstly, the injury must be defined. Even cases with complete transection may be overlooked, and a scrupulous inspection of the gland must be carried out in all cases. Upper abdominal haematomata should always be considered as presumptive evidence of a damaged pancreas; they must be opened and evacuated so that the underlying trauma can be inspected. The sites of rupture most commonly missed are in the head of the gland and on the dorsal surface of the body and the tail.

Secondly, haemorrhage must be controlled. The bleeding pancreas not controlled primarily is never controlled, and reactionary and secondary haemorrhage have presented major problems in all the large reported series. However, primary haemorrhage is more likely to originate from some large vessel in the vicinity of the pancreas than from arteries or veins 
within the gland itself, and these main structures should always be identified and examined.

Thirdly, whatever the extent of the pancreatic injury drainage must be instituted, and it is now widely agreed that this should preferably be of the sump suction type. A pancreatic fistula may develop, but this should be seen not as a failure of treatment but rather as a desirable alternative to a pseudocyst or later abscess formation.

Fourthly, pancreatic tissue should be preserved. This is perhaps the least important of the therapeutic principles, for it has been well established for many years ${ }^{4}$ that the gland has an enormous functional reserve, and neither exocrine nor endocrine insufficiency is likely even with $85-90 \%$ resection.

The various technical manoeuvres which may be required to deal with the actual damage to the gland have been well reviewed by Donovan and his team. ${ }^{5}$ If there is simple contusion then drainage alone will suffice, but if the capsule is breached there has been a clear move in recent years towards resection if this is possible. ${ }^{16}$ The pancreas is quite commonly split across the vertebral column, particularly in steering wheel injuries, and in such cases left pancreatectomy is considered preferable to the more complicated internal drainage procedures utilizing a Roux loop. ${ }^{7}$ When the head of the pancreas is ruptured, perhaps with an associated duodenal injury, the situation is much more dangerous, and Donovan et al. ${ }^{5}$ have advocated antecolic Polya partial gastrectomy with duodenal drainage for this type of case. This might seem a formidable undertaking in an ill patient, but their case reports are convincing and their overall results have shown continuing improvement with a steady fall in morbidity and mortality.

In the general management of these difficult problems Adwers and Davis ${ }^{9}$ have suggested that parenteral hyperalimentation may help to suppress pancreatic secretion as well as support the patient, particularly if a pancreatic fistula should develop. They have tested this theory in the laboratory with good results, but more clinical studies will be needed before all their claims can be accepted.

1 Yellin, A. E., Vecchione, T. R., and Donovan, A. J., American fournal of Surgery, 1972, 124, 135.

2 Olsen, W. R., Fournal of Trauma, 1973, 13, 200.

3 Northrup, W. F., and Simmons, R. L., Surgery, 1972, 71, 27.

4 Dragstedt, L. R., Haymond, H. E., and Ellis, J. C., Archives of Surgery, 1934, 28, 232 .

1934, 28, 232.
5 Donovan, A. J., Turrill, F., and Berne, C. J., Surgical Clinics of North America, 1972, 52, 649.

6 Weitzman, J. J., and Rothschild, P. D., Surgical Clinics of North America, $1968,48,1347$

7 Jordan, G. L., Overton, R., and Werschky, L. R., Southern Medical fournal, 1969, 62, 90

8 Jones, R. C., and Shires, G. T., Archives of Surgery, 1971, 102, 424.

Adwers, J. R., and Davis, W. C., Surgery, Gynecology and Obstetrics, 1974, 139,514 .

\section{Injudicious First-aid}

A recent press report ${ }^{1}$ gave details of the death of a 64 -year-old woman which may well have been caused by injudicious firstaid. The woman collapsed while shopping, gasped, and was presumed by a state-registered nurse to have suffered from a heart attack. While an ambulance was sent for, artificial respiration was given and the nurse did heart compression. She continued to give heart compression in the ambulance. At hospital, the woman was given cardiac massage by ambulance staff in the presence of a consultant. The pathologist reported to the coroner that in his opinion the cause of death was "bleeding into the peritoneum and right pleural cavity due to or as a consequence of tears and lacerations of the liver, and fractured ribs due to or as a consequence of excessive attempts at resuscitation. No underlying disease was found which would have caused her collapse."

The coroner, as is usual in such cases, recorded a verdict of death by misadventure. There will be sympathy for all concerned in this tragedy, but what are the lessons to be learned?

Firstly, there should be a wider appreciation of the relative frequency of the emergencies which may respond to appropriate life-saving first-aid. Traditional first-aid training lays little or no stress on the prevalence of these conditions nor on the dangers associated with certain resuscitation techniques. Lives can be saved by prompt, effective treatment, but most of these are in persons unconscious or bleeding-for example, about a quarter of the road casualties who die are not seriously injured: they die from obstructed breathing. Experienced doctors and first-aiders will have lost count of the number of people successfully treated at the roadside for unconsciousness and bleeding, but they will probably recall few occasions outside hospital when heart compression and artificial respiration were necessary. It must be stressed that compression should not be given if it is not necessary and may be positively dangerous.

Second, therefore, in the lessons to be learned, is the need to identify heart stoppage and circulatory failure before beginning heart compression. Diagnosis must precede first-aid; and for that reason training in the technique of heart compression should be limited to experienced personnel. One first-aid book $^{2}$ states clearly that "heart compression (closed chest cardiac massage) has been omitted from this book. We think that it is a technique which is too difficult and potentially dangerous for the basically trained first-aider." Those who are trained in heart compression should be sufficiently instructed not only in theory but also in practice with the use of models, so that they can use the procedure safely and be aware of and able to avoid its potentially lethal dangers.

\footnotetext{
1 Eastern Daily Press, Norwich, 11 January 1975.

2 Gardner, A. Ward, and Roylance, P. J., New Essential First-aid. London, Pan, 1972, p. 14.
}

\section{Medical Implications of Oil Related Industry}

The continuing expansion of the offshore gas and oil industry in the northern North Sea is leading to a rapid rise in the numbers of men living and working on structures which may be up to 150 miles distant from the nearest landfall and in latitudes extending from the Yorkshire coast to 100 miles northward from the Shetlands. At present some 5000 workers are involved, of whom about 700 are engaged as divers operating in depths down to $200 \mathrm{~m}$ and occasionally more. By 1980 these figures may have risen to $10000-12000$ workers with 1000 divers, and the depths at which they will be working will be greater as exploration moves off the continental shelf. Medical problems are being created by this new industry, and the urgency of the situation led the B.M.A. Scottish Council last month ${ }^{1}$ to convene a special committee under the chairmanship of Dr. J. S. McCrae to consider the subject.

Unlike other areas of offshore oil exploration in the world the northern North Sea poses problems resulting not only from the depth of sea but also from the inclemency of the elements-gale force winds and cold are features not confined to the winter in these high latitudes. Such physical conditions 